\title{
A Corpus-Based Study of Semantic Collocations of the Verb "Feel" in English Public Speaking Setting: Chinese EFL V.S Native Speakers
}

\author{
Huijuan Wang ${ }^{1} \&$ Yufeng Zou ${ }^{1}$ \\ ${ }^{1}$ Northwest A\&F University, Yangling, China \\ Correspondence: Yufeng Zou, No.22 Xinong Road, Yangling, Shaanxi, China 712100. E-mail: \\ zouyufeng@nwafu.edu.cn
}

Received: August 18, 2018

Accepted: October 20, 2018 Online Published: December 29, 2018

doi:10.5539/ijel.v9n1p251

URL: https://doi.org/10.5539/ijel.v9n1p251

\begin{abstract}
As great importance has been given to English in China, English public speaking is becoming an important part in students' English learning. Meanwhile, many forms of English speaking contests have been flourishing in China over two decades. However, analysis of semantic prosodies in public speaking setting is relatively complex and subjective due to the difficulties in describing the evaluative meanings and the attitudes as intended by the speaker. This paper is a contrastive study of semantic prosody of the word feel which was concordanced from two sub corpora (CES_S and CES_C) from a self-built corpus (Corpus of English Speeches(CES)), aiming to explicitly reveal how EFL learners are different from native speaker when using a word with specific semantic prosody in English public speaking setting. The results show that there is no significant difference between Chinese students (EFL learners) and U.S and UK celebrities (Native English speakers) when they use the word feel with positive semantic preference in the context of delivering a speech, but EFL learners tend to express more positive emotions towards their counterparts than they do to themselves. In addition, the EFL learners have higher frequencies in using the word feel with the negative environment than the native English speaker do. This paper thus offers additional information on choosing the right semantic collocation and provide instructional guidance for English public speaking teaching and learning in China.
\end{abstract}

Keywords: corpus-based, semantic prosody, Corpus of English Speeches (CES), feel, semantic collocation, EFL learner, native speaker

\section{Introduction}

In today's job market, demands for the academic disciplines, the versatility and competitiveness have prompted scholars, educators and researchers to emphasize the importance of learners' success in handling oral communication skills and public speaking skills (Tamimi, 2016). With the growing demand for good command of English especially speaking skills in China, millions of students have participated in the various English speaking contests over the last two decades, and in recent years most of the universities in China have taken English public speaking into their curriculum as either compulsory or elective. As a form of learning to speak a foreign language, learners should not only focus on grammatical and semantic rules but also acquire the knowledge of how native speakers use the language in the context of structured interpersonal exchange, in which many factors interact (Kang, 1997). Therefore, it is necessary to examine the semantic and collocational features of public speaking genre from both EFL learners and native speakers by corpus-based method, hoping to explore some meaningful implications with objective data or evidence for EFL learners in English public speaking setting.

The idea of semantic prosody was originally put forward by Sinclair in 1987, but the concept and term of semantic prosody was first introduced in 1993 by Bill Louw (Whitsitt, 2005) and it has since become an important part of corpus-based linguistic research claiming more attention from the linguists and researchers. Sinclair (1987) was the first to notice the phenomenon of semantic prosody in the collocational behavior of words and this built the foundations for the upsurge of several definition schemes for the concept. Greenbaum (1974) defines collocation as "a frequent co-occurrence of two lexical items in a language" and Hoey (1991) adds that the term collocation can only be used if a lexical item co-occurs with other items with a greater than random probability in its context. 
Since the introduction of the concept of semantic prosody by Louw (1993), numerous studies from various authors such as Bublitz (1996); Hunston (2007); Partington (1998, 2004); Stubbs (1995); Phillip (2009) and Sinclair $(1996,2004)$ have been done focusing on the corpus-based semantic prosody researches. Studies have been conducted on several cases of semantic prosody in English such as happen, set in, naked eye, true feelings (Sinclair, 1987, 1991, 2004), build up (Louw, 1993), cause and happen (Bublitz, 1996), break out (Stubbs, 1995) etc. Harris, Gries and Miglio (2014) and Wang and Wang (2005) state that prosodies can be used in many aspects of human communication whence it can indicate the mental or emotional state of a speaker, the meaning of a sentence (such as prosodic representation of irony to invert the truth value of the literal interpretation), the importance of a character or a concept in a narrative, emphasis etc.

This paper first takes a critical look at the concept of semantic prosody by underscoring the underlying tenets and concepts that define it. The paper then considers specific English speeches delivered by EFL learners, in particular Chinese students as well as public speeches of some world celebrities and leaders (presidents, prime ministers, renowned writers and etc.) with the aim of identifying the use of the concept of semantic prosody. This is done by an initial evaluation of the semantic prosodies (grouping them as positive, neutral or negative) and taking into consideration the words that collocate the selected nodes before analyzing the attitude of the prosodies. The paper then discusses the complexities identified in the analysis of the two categories of speeches with the aim of pointing out specific areas of importance. This is necessary because the findings herein will provide the foundations for future studies to enhance effective analysis of register-specific contexts as well as some insightful suggestions for EFL learners to produce better English speeches in public setting.

\section{Literature Review}

\subsection{Semantic Prosody}

Several definition schemes for the concept of semantic prosody followed Sinclair's discovery of the collocational behavior of words in 1987. Louw (1993) defined semantic prosody as "a consistent aura of meaning with which a form is imbued by its collocates" after coining the term. In his definition, Louw holds the linguistic position that form and meaning are inseparable hence semantic prosody maintains both the semantic meaning and the pragmatic meaning (Zhang, 2010).

Sinclair $(1996 ; 2004)$ states, "the initial choice of semantic prosody is the functional choice which links meaning to purpose as all subsequent choices within the lexical item relate back to the prosody". A closer look at this definition points out to three important aspects of semantic prosody namely functionality, linguistic choice, and communicative purpose. The initial choice of a sentence is always at the functional level of the semantic prosody; this means that the choice of lexical items to make a sensible sentence that follows the grammatical rules must take into consideration the semantic preferences and semantic prosody which points to the functions (Sinclair, 1996; Zhang, 2010). The linguistic choice is part of semantic prosody because the combination of every collocation in a sentence is not arbitrary but the words used are mutually related (Zhang, 2010). The attitude of the speaker can be derived from the functionality of the node word. For instance, a speaker chooses a lexical item to make a sensible sentence which follows the lexical and grammatical rules, but then, both semantic presence and semantic prosody must be taken into consideration since they point out the functions because the initial meaning choice is at the functional level of the semantic prosody (Sinclair, 1996). Secondly, Sinclair (1996) asserts that the combinations of collocations always follow a mutual selection relation and thus are not arbitrary. Finally, Sinclair (1996) asserts that the right semantic prosody is bound to express the attitude of the speaker or writer and their purpose with harmony and explicitness.

On the other hand, semantic prosody has been defined as "a particular collocational phenomenon" with a collocation being the habitual co-occurrence of two or more words (Zhang, 2010). Prosody is often described as how words can be identified with positive and negative relations in the course of frequent occurrences with specific collocations; it can thus be categorized into negative, positive, or neutral (Zhang, 2010). According to his definition, Stubbs (1995) emphasizes that collocation and semantic prosody are related and are both subject to the co-selection of the lexis.

According to Hunston and Francis (2000), semantic prosodies are in simple terms words that co-occur with other words that belong to specific semantic sets. This implies that semantic prosody is a phenomenon where the core word occurs together with specific items of lexical nature which belong to a semantic set.

Partington (1998) explains the term semantic prosody as the "spreading of connotational coloring beyond single word boundaries". He categorizes semantic prosody into negative and positive; where a prosody that offers a pleasant/favorable meaning is termed as positive while those offering unfavorable meanings are termed as negative, and if the affective meaning is neutral (or where there is no evidence of any semantic prosody), it is 
termed as neutral. In his study, Partington (1998) outlined several examples using the word commit to underscore the essence of prosodies being either positive or negative:

... "With grievous bodily harm if they commit a deliberate foul resulting in...

$\ldots$ if he is committing or about to commit an act likely to endanger life. An....

$\ldots$ and one of conspiracy to commit deception. The deception charges...

...of those who drink alcohol do not commit offences of violence thereafter.

... for an IRA bombing she did not commit. Or the accused in the....

...offence of hacking with intent to commit serious crime _ including all....

...eventually starve to death or commit suicide. Although skeletally thin...

...perfect environment in which to commit these offenses. Detective...

In the above given examples, Partington (1998) says that the unfavorable connotation can be seen to reside not only in the word commit but over a unit consisting of commit and its collocates. This agrees with Stubbs' (2013) argument that it is the context of the core that determines the semantic prosody of a unit of meaning.

Louw's (1993) definition of semantic prosody fails to illuminate the functions of semantic prosody; it does not offer the pragmatic meaning of the concept either. Snubbs' (1996) definition, however, only depicts a partial picture of the concept of semantic prosody because it suggests that semantic prosody is a simple collocation without taking into consideration the entire synopsis of both semantic and pragmatic meanings of the concept. Partington's (1998) definition is more or less similar to that of Louw (1993) because it fails to emphasize the pragmatic aspect of the concept implying that it is simply a way of conveying connotational meanings. Hunston and Francis' (2000) definition is rather shallow and fails to add value to the previous definitions by corpus linguistics; the term semantic set that it introduces is rather ambiguous thus making the definition insufficient to give a comprehensive illustration of the concepts of semantic prosody.

A closer look at the definitions offered by different authors reveals several aspects of semantic prosody. The authors' differences are mainly due to their individual points of emphasis. Therefore, by taking into consideration all the definitions given above, it can be concluded that collocates of a word may form a semantic class that can be characterized by its attitudinal meaning. Such a semantic class is what is termed semantic prosody.

\subsection{The Role of Corpus Analysis in Identifying Semantic Prosody}

As mentioned earlier, various authors believe that the complexity in studying semantic prosody requires an involvement of computational analysis because of the large amounts of data that must be taken into consideration. Hunston (2002) states that semantic prosody "can be observed ONLY by looking at a large number of instances of a word or phrase since it relies on the typical use of such word or phrase"; therefore, Louw (1993) asserts that semantic prosody is a phenomenon that can only be revealed computationally and whose extent and development can only be properly traced by computational methods".

Identification of semantic prosody is thus an important aspect of its analysis; Stewart (2010) claims that intuition plays an important role in identifying semantic prosody in any corpus data. This is in line with McEnery and Wilson's (2001) view that corpus-based and intuition-based approaches are complementary in the identification of semantic prosody in corpus data. Therefore, it is evident that semantic prosodies add meaning beyond the meaning already expressed by word-semantics thus requiring closer examination of the contexts and meaning components that may not be detected around the core word (Sorli, 2013). In as much as the corpus texts facilitate the retrieval of the recurrent patterns without allowing the analysis of the context of the situation, it allows identification that is crucial for the analysis.

Having asserted that semantic prosodies are not merely connotations, the identification and description of semantic prosodies from practical analysis of corpus data is often difficult. Such difficulties in clearly and succinctly describing semantic prosodies in corpus data causes most analysts to loosely speak of positive and negative prosodies rather than attempt to articulate the prosodies more precisely (Phillips, 2009).

Partington (1998), Louw (2000), and Xiao and McEnery (2006) agree that semantic prosody spreads the meaning of a word or phrase beyond single word boundaries and its function is to express the speaker/writer attitude or evaluation. In this analysis, Partington's (2004) positive (favorable), negative (unfavorable), and neutral prosodies are taken into consideration by evaluating each case in context to ascertain the favorability or the unfavorable affective meaning of the sentence. This study explores the varied interpretations of corpus 
evidence obtained from the EFL learners' speeches and some speeches from celebrities of English native speakers.

\section{Method}

The data set for this study was obtained from a self-built small scale corpus, Corpus of English Speeches (CES) with a sub-corpus of English speeches given by some Chinese college students who participated in various national speech contests (CES_S: 8018 types, 68000 tokens), and another sub-corpus of free speeches that were presented by some speakers in functions in the US and UK (CES_C: 21426 types, 148565 tokens). After a preliminary look at the CES, it can be easily found the top ten ranking verbs are as follows: (linking verbs, modal verbs and auxiliary verb are excluded from this study)

\begin{tabular}{cccccccccc}
\hline say & know & see & live & want & think & call & ask & use & feel \\
\hline 499 & 402 & 331 & 292 & 256 & 221 & 218 & 213 & 207 & 198 \\
\hline
\end{tabular}

From the above 10 lexical verbs with high frequency, the verb feel is specifically considered for semantic analysis in this study, because it is more likely to collocate with the words that have semantic preferences. The word feel has an array of dictionary definitions as a transitive or intransitive verb, as a noun, or even as a pronoun However, it generally refers to becoming aware of something through the skin, through the sense of touch, or to experience an emotion or other mental state about something. It also means to become aware of something or to experience a consequence of something. It is also used to refer to an intuitive ability.

The availability of numerous corpus-analysis software that avail word lists, word frequencies, concordances, and key words provides a base for the choice of Anton 3.5.2 linguistic tool for this analysis. Its convenience and user-friendly interface offer the ability to extract a list of co-occurrences with a given search word. The search process utilized in this study is presumed not to influence the results. Searching by lemmas that allow finding of different forms of lexical units in a single search was not utilized because a single search would have automatically included other forms of the word feel, such as feeling, felt, and feels. Thus, the grouping of results by lemmas was also not conducted. However, the collocates of verb form feel, felt, and feels were analyzed by using the KWIC (Keyword in Context) method through the concordance lines.

\section{Results}

\subsection{Concordance of the Results of Semantic Prosodies}

By a quick search in the corpus, it is found that the word feeling is only used as a noun which, it is opined, is not a $v+i n g$ form, thus only feel, feels and felt were taken as the node words for the collocational concordance for semantic prosody. The total numbers found in CES_S and CES_C are 81 and 117 respectively (See Table 1). Further analysis follows for the detailed semantic preference study.

Table 1. Frequencies of "feel" in CES

\begin{tabular}{llll}
\hline Semantic Prosody & CES (freq) & CES_S (freq) & CES_C (freq) \\
\hline positive & 34 & 16 & 18 \\
negative & 44 & 28 & 16 \\
neutral & 120 & 37 & 83 \\
Total & 198 & 81 & 117 \\
\hline
\end{tabular}

\subsection{Positive Semantic Prosodies}

This prosody was found 16 times in the CES_S and 18 times in the CES_C with collocations of words from conjunctions, prepositions, verbs, modals and verb + DON'T with the word feel (See Figure 1 \& Figure 2). 
... without love, but fortunately we can still feel the warmth expressed by love, just... ...world, and you will find it rewarding to feel the warmth of life. Take courage and... ... it in the dormitory or on the campus. I felt more proud then ever for my team... ...ling down before you. I bet you would feel comfortable with such a social pattern... ...still lingers. In information age, we do feel fortunate to enjoy the technological stuff... ... good morning, ladies and gentlemen: I feel very honored and delighted to give you a.. ...think the world is not unrecognizable, I feel fearless to the unsolved problems. With...

...Faith is unique, just as happiness is. We feel happy for different reasons, we believe... ...thing. When I am singing on the stage, I feel whole-heartedly involved, and the...

...message 75 altogether, my phone said. I felt delighted about the large number. But...

... ideas, and new ideas always make her feel young. "Compared with the late 70s, "...

.... it in the dormitory or on the campus. I felt more proud then ever for my team, because...

...transportation or the Internet, when people felt nostalgic, they often released their emotions...

... streets with joy. After years of unrest, he felt a sense of belonging and new possibilities...

... with all all kinds of drinks handed to me. I felt a kind of warmth I had never felt before...

... picking up trash from the ground, when I felt their enjoyment and harmonious relationship...

Figure 1. The concordance of the results of feel with positive prosodies in CES_S

...they do. So, for example, we smile when we feel happy, but also, when we're forced to...

...ng a pen in in our teeth like this, it makes us feel happy. So it goes both ways. When it...

.... be powerful, you are more likely to actually feel powerful. So the second question really...

...ppy. So it also goes both ways. So when you feel powerful, you're more likely to do this...

...to stand like this, and it's going to make you feel more powerful." So this is what we...

...is. We then ask them, "How powerful do you feel?" on a series of items, and then...

... lead the way. In 1984, my heart is made to feel glad because I know there is a way out ...

...payer, because it's my money and they must feel accountable. I believe in an ...

...he refused. Evidently, the District Attorney felt safe to use the notes of a patrolman...

... longer identify the boundaries of my body, I felt enormous and expansive. I felt at...

...of my body, I felt enormous and expansive. I felt at one with all the energy that was...

...stress related to my job -- it was gone. And I felt lighter in my body. And imagine...

..ted to any of those -- they were gone. And I felt this sense of peacefulness. And...

...lose 37 years of emotional baggage! Oh! I felt euphoria. Euphoria. It was beautiful...

..air,just, just right out of the balloon, I just felt my energy lift and just -- I felt my spirit...

...pleasure that I find myself in Pueblo, and I feel it a compliment in this beautiful hall...

...st of their own. Does not every American feel that assurance has been added to...

... to share with all free peoples, we shall, I feel confident, conduct our operations...

Figure 2. The concordance of the results of feel with positive prosodies in CES_C

This reveals that the word feel has various abilities and functions. It is obvious to note that when the word is used after a noun + DON'T, DIDN'T, or negative adverbials, then a negative emotion, the attitudinal meaning of the whole statement becomes positive. But in this study, only the collocational meaning of the word feel is considered. Therefore, the semantic preferences of feel only depend on the words meaning that collocates with the node feel in this study.

.... and met so many people, but didn't feel uncomfortable at all, because I know even...

...those very first days on campus, I no longer feel perplexed, because I now have my...

...-eat-dog wild jungle. What's worse, we barely feel guilty about the conducted evils ...

4.3 Negative Semantic Prosodies

The frequencies of negative prosody found in CES_S and CES_C are 28 and 16 times respectively. (See Figure 3 and Figure 4) 
... he very first time in my life; I could feel the nervousness threatening to bring ... ... the audience, I am sure that you all feel the embarrassment I had when I first ... ... ver before. But do you sometimes feel imposed by the technology when the ... ...he technology, at the same time, we feel stressful and moreover enslaved.Tech... ... sbout us sharing a crowded dorm, I feel isolated if I live and eat alone. Even... ... ur own culture. Why do we have to feel compelled to take sides? Why should... ... elled to take sides? Why should we feel guilty about being plural in a cultural ... ... nes, friends and ourselves. We may feel embarrassed and insulted. But showing ... ... anicked in face of disasters. I could feel an overwhelming force behind me, an... ... e to teach me how to love make me feel I am experiencing a disoriented and ... ... belief should not be something you feel trapped within. Ladies and gentleman... ...m, confronted with difficulties, they feel lonely and helpless. Without love, ...

... wspaper this way. But she started to feel sympathy for it. She sent the sponsor ... ...tive and are guaranteed to make you feel really, really bad about yourself! No... ... e said. when I was young, I always feel cold, and dark. My first dream was to ... ...threatening to bring me down, and I felt cheated by my teacher: it was impossible... ...ttoo long ago, many Chinese people felt terribly sad when they heard the shocking... ... hey were forced to work. Many also felt bitter on hearing of the death of the 22-year... ...ng. After watching a tragic movie, I felt really depressed and ask my roommates to... ... the first girl argued. The second girl felt uncomfortable and yelled, "No! How can you... ... When I first saw this speech topic, I felt extremely confused about the word humanism... ...way. I used to be very shy and often felt lonely. Although I did well in all the academic...

... nd met so many people, but didn't feel uncomfortable at all, because I know even though...

... first days on campus, I no longer feel perplexed, because I now have my own guideline...

... jungle. What's worse, we barely feel guilty about the conducted evils because what we...

... in nervousness; no longer did I feel the hospital's tense cloud of anxiety; no longer did...

... ted as.Miss you too.She doesn't feel bothered at all by the variety of languages she...

... nd the start line, I no longer felt lonely or afraid. I saw my classmates standing...

Figure 3. The concordance of the results of $f e e l$ with negative prosodies in CES_S

...with which we began this second term, I feel a great sadness that I will not be...

... that moment comes, it's really okay to feel bad for a little while. Give yourself time...

...do this kind of thing than men. Women feel chronically less powerful than men, so this...

...ist the problems which cause people to feel cynical, angry, frustrated: problems...

...us, and we're alone in our feelings. We feel forgotten. Well, the fact is that we are...

...ould say to you today: The anger you feel is valid, but you must not allow yourselves...

...ne layer, that's wrong. No wonder we feel isolated and confused. We want answers and...

...to to be consumed by it. The hurt you feel must not be allowed to turn into hate...

...to the search for justice. The loss you feel must not paralyze your own lives. Instead...

...hese things I am grateful to you. But I feel no exultation, no sense of triumph. Our...

...x. At this point, late 1982, I began to feel severe stress on the job. I began to...

...to sit in that wheelchair all day and feel sorry for himself so with prosthetics he...

... full impact of this tragedy. But we feel the loss, and we're thinking about you...

....say, "I'm just so grateful, because to feel this vulnerable means I'm alive." And the...

... only a few people come, and usually feel uncomfortable? It was not until some of...

... $r$ purpose and meaning, and then we feel vulnerable, so then we have a couple of...

Figure 4. The concordance of the results of feel with negative prosodies in CES_C

\subsection{Neutral Prosodies}

Apart from positive and negative collocational preferences, the word feel has been used for 120 times in settings that fail to clearly show positive or negative feelings (in instances where the emotions referred to are neither negative nor positive). Such instances show the use of a neutral prosody for the word. In most instances, feel has been used in reference to a desire or personal experience about a situation. Some of the neutral prosodies that failed to present a positive or negative setting are shown below. The use of the word feel in a neutral context for the celebrities also followed a similar pattern presented by the EFL speakers. They fail to out rightly reflect a positive or a negative emotion but a large number of the sentences show a conviction rather than emotion. (See Figure 5) 
.... and close, something that we can see, feel and touch. It will answer ... ... 's minds; our hearts are supposed to feel each other's hearts and th... ... what I see, what I listen and what I feel. My past experiences attest... ...conversation carried out, nor do we feel the need to talk to such as ... ...ve concert with a friend, to actually feel the tiniest movement of the... ...erbals do govern how we think and feel about ourselves, so it's not... ... govern how other people think and feel about us. There's a lot of ... ....at involves Berlin's whole look and feel and way of life - not mere... ...le, I would only say that I can also feel in my own heart the same ... ...e it, or hear it on the news or even feel it in our daily lives but I $h . .$. ...banana nut muffin. I don't want to feel these. And I know that's $r .$. ....atient and to bide their time. They feel - they know, indeed - tha ... ...ennedy, I want to express what we feel to those who mourn with...

Figure 5. Concordance examples of feel with neutral prosodies in CES

From Figure 1 and Figure 2, it can be seen that the word feel is mostly used to express positive emotions of the speaker or the person referred to. This implies that if the word feel is taken as the node, then the prevailing corpus pattern reflects some form of emotion. The most commonly preferred collocations that show positive implication in EFL learners' speech include, happiness, okay, proud, warmth, young, honored, sympathy, fortunate, fearless, comfortable etc. These collocates that follow the core word construct a context of a satisfied state of mind regarding the prevailing status. The findings indicate how EFL learners use the word feel in the context of good emotions that follow satisfaction and acceptance when they deliver an English speech. The most significant collocate of the word feel in the US and UK speeches includes happy and powerful. These two most common collocates are important pointers to the intuitive meaning intended by this category of speakers. Feeling powerful can be taken to reflect the ability of an individual to have authority, be respected and command a following. This can also be linked with the happiness that is commonly mentioned in the speeches. The use of the word feel in the various prosodies vividly shows the in-born thoughts of the US and UK speakers. It thus helps underscore the importance of the syntactic context of a word in studying it.

\section{Discussion}

\subsection{The Attitudinal Contexts of Lexical Items}

There has been a great reliance on two types of consistency to discuss semantic prosody of the word feel in this analysis, namely consistent co-occurrence of linguistic items as coined by Partington (2004), and the consistency in discourse function of a sequence of items as coined by Sinclair (2004). In this analysis, the verb feel has been shown to be mostly associated with negative things in as far as the collocates are concerned. For instance, the most significant collocates that frequently occur with feel in the EFL learners' speeches are the word guilty, embarrassed, and bad. These words just depict emotions associated with the prevailing status of events. Embarrassment, in this context, is used to register the frustration that follows the inability to reciprocate or meet the expectations of others in given situations. Likewise, guilty and bad are used to show the emotions that follow the inability to meet specific expectations.

In the native English speeches, the verb feel has been mostly used in the negative context hence construing a negative prosody. The speakers frequently used the collocates isolated, powerless, and vulnerable with the word feel. These words represent a state of loneliness and an inability to face the challenges that an individual encounters in life. Therefore, a consistent use of these terms with the node indicate the internal fear of the speakers, and without studying the contexts of the node, it becomes difficult to discover the inferred meaning of the word. From the use of the collocates as indicated, it can be intuitively understood that these celebrities dread loneliness and being vulnerable.

\subsection{Attitudinal Meaning Based on Register-Specific Corpus}

Sinclair (1991), in analyzing the word budge, noted that the most frequent phraseology around the word involved a negative (lack of willingness from an individual rather than the first person). However, after considering the discourse function, he also noted that the phraseology reflected an expression of frustration in the face of difficulty (Sinclair, 1991). (Hunston, 2007) stated that register-specific nature of semantic prosody; for instance, the word favor may imply positive evaluation if associated with human and animate experiences. It may however lose its positive evaluation when it occurs in scientific phenomenon and other inanimate objects. Likewise, in our analysis, when the verb feel is used in the context of an inanimate being (or when it collocates with a noun) or when the sentiment is about another human or animal, the overall attitudinal meaning tends to be positive 
mainly in the EFL learners' speeches.

... the newspaper this way. But she started to feel sympathy for it. She sent the sponsor all...

...civilians of the date can hardly see and feel the humanism, she devoted herself to ca...

However, the verb feel is commonly used by the Chinese students when referring to their individual selves in a negative context. This implies the attitude of the Chinese students towards themselves.

...said when I was young, I always feel cold, and dark. My first dream was to grow...

...forgetting our own culture. Why do we have to feel compelled to take sides? Why should...

...to feel compelled to take sides? Why should we feel guilty about being plural in a cultural...

... suppose to teach me how to love make me feel I am experiencing a disoriented and twisted...

Since the EFL learners use the word feel in the context of their attitudes towards self and others, it can be inferred that EFL learners express more positive emotions towards their colleagues than they do to themselves. This is contrary to the native English speakers who tend to use the verb feel with more positive collocations on themselves than on other people.

....share with all free peoples, we shall, I feel confident, conduct our operations as...

...the way. In 1984, my heart is made to feel glad because I know there is a way...

...do. So, for example, we smile when we feel happy, but also, when we're forced to...

...in our teeth like this, it makes us feel happy. So it goes both ways. When it...

...that I find myself in Pueblo, and I feel it a compliment in this beautiful hall.

...more confident, more optimistic. They actually feel that they're going to win even at...

And when I hold that grandbaby, I feel the continuity of life that unites us, that...

An analysis of the native English speeches also revealed that the verb feel was more often used on the negative milieu to refer to their emotions towards situations and conditions rather than other people or animals.

From the analysis above, it is evident that the two groups of speakers derive the attitudinal meaning of their sentences containing the verb feel by considering the targeted item. This analysis follows Sinclair's (1991) claim that some speeches derive their discourse function from specific registers. When delivering a speech, EFL learners more often use the word feel in a positive setting while talking about other animate beings and in a negative setting while referring to themselves (the speakers). Native English speakers, however, use the word feel in a positive setting while talking about themselves and in a negative setting while talking about emotions derived from various situations or conditions.

\subsection{Semantic Prosody Is Not Simply a Form of Connotation}

Stewart (2010) views semantic prosody as virtually synonymous with evaluative connotation and thus a subset of connotation. However, connotation is located in the part of the meaning that is not shared equally by all of the speakers of a language since it is intrinsically psychological (Sorli, 2013). Therefore, connotation is recorded in the mental lexicon of the speaker hence not conventionalized to the same extent as semantic prosody, which is linked to a concrete context of the situation.

A closer look at the two corpora reveals that semantic prosodies are not merely a type of connotative meaning. This is because the shallow meanings cannot be practical in lexical units that carry semantic prosodies (Sorli, 2013). The under-specified peripheral meanings cannot be identified introspectively and are thus defined by their context and use. In our context, Partington (2004) puts clearly that connotation is a very 'versatile' concept as it covers varied aspects such as social connotation, cultural connotation, and expressive connotation. Considering Partington's (2004) view, it is evident that both social and cultural connotations play a crucial role in the use of the word feel by the two categories of speakers. By aptly evaluating the Chinese (who are derived from communistic/socialistic environments) and the U.S and UK (who are derived from capitalistic environments) speakers' corpora, it is evident that the social and cultural aspects of connotation play a role in shaping their speeches.

\section{Conclusion}

The word feel, as a core, shows extended units of meaning but most predominantly on the negative framework. This is because the verb feel mostly collocates with items of unpleasant nature, in this case emotions. However, it is important to underscore as stated by Berdnarek (2008) that co-occurrence of an item with the negative 
collocates does not automatically show the presence of negative connotation.

Similar to most other research findings, this paper has shown that an evaluative meaning of a phrase or a word is associated with the specific details of the sentence's phraseology. This implies that an attitudinal meaning derived by a look at a set of concordant phrases is not sufficient to support conclusions about the meaning of a word or phrase. Moreover, the reason why an item is chosen for use, over and above the semantic preferences is its prosody. To sum up, this study largely considered evaluative and attitudinal meanings derived from the core word with its collocates with specific emphasis on registers. Future research can proceed to examine the functional and structural variations in the sentence's structure, such as the colligations relative to the core's collocations linked to specific registers.

\section{Limitations}

In this paper, the aim was to consider all the aspects mentioned by the different authors who coined the meaning of the term semantic prosody. But the corpus analysis methodology utilized in this study may not be exhaustive because the list of co-occurrences noted only includes lexical units that occur in the vicinity of the search word, feel. This means that the other expressions that may have been used figuratively to describe the emotion could not have been detected where the word feel was not mentioned.

In addition, the corpus studied may be considered limiting due to the small size; this may not have provided the actual picture of the representation of the core word among the two groups of speakers. Hunston (2002) stated that semantic prosody "can be observed only by looking at a large number of instances of a word or phrase". Consequently, the findings in this study would be helpful in generating a foundation for a study similar based on much larger corpus.

\section{Acknowledgement}

This study is sponsored by Northwest A\&F University Research Project (Grant No.2015RWYB29)

\section{References}

Anthony, L. (2010). AntConc (Version 3.2.1) [Computer Software]. Tokyo, Japan: Waseda University.

Atef Al-Tamimi. (2016). Public Speaking Skills Needs of English Majors at Universiti Sains Malaysia. LSP International Journal, 1(3), 31-42.

Bednarek, M. (2008). Semantic preference and semantic prosody re-examined. Corpus Linguistics and Linguistics Theory, 4(2), 119-139. https://doi.org/10.1515/CLLT.2008.006

Bublitz, W. (1996). Semantic prosody and cohesive company. Leuvense Bijdragen, 85(1-2), 1-32.

Greenbaum, S. (1974). Some verb-intensifier collocations in American and British English. American Speech, 49, 79-89. https://doi.org/10.2307/3087920

Harris, M., Gries, S., \& Miglio, V. (2014). Prosody and its application to forensic linguistics. Linguistic Evidence in Security, Law and Intelligence, 2(2), 11-29. https://doi.org/10.5195/LESLI.2014.12

Hoey, M. (1991). Pattern of Lexis in Text. Oxford: Oxford University Press.

Hunston, S. (2002). Corpora and Applied Linguistics. Cambridge: Cambridge University Press. https://doi.org/10.1017/CBO9781139524773

Hunston, S. (2007). Semantic Prosody revisited. International Journal of Corpus Linguistics, 12(2), 249-268. https://doi.org/10.1075/ijcl.12.2.09hun

Hunston, S., \& Francis, G. (2000). Pattern Grammar-A Corpus-driven Approach to the Lexical Grammar of English. Amsterdam/ Philadelphia: John Benjamins. https://doi.org/10.1075/scl.4

Louw, B. (2000). Contextual prosodic theory: bringing semantic prosodies to life. In C. Heffer, H. Sauntson, \& G. Fox (Eds.), Words in Context: A Tribute to John Sinclair on his Retirement. Birmingham: University of Birmingham.

Louw, E. (1993). Irony in the Text or Insincerity in the Writer? The Diagnostic Potential of Semantic Prosodies. Text and Technology: In Honour of John Sinclair, 157-176. Amsterdam: John Benjamins. https://doi.org/10.1075/z.64.11lou

McEnery, T., \& Wilson, A. (2001). Corpus Linguistics. Edinburg: Edinburg University Press.

Partington, A. (1998). Patterns and Meanings - Using Corpora for English Language Research and Teaching. Amsterdam/Philadelphia: John Benjamins. https://doi.org/10.1075/scl.2 
Partington, A. (2004). Utterly content in each other's company: Semantic prosody and semantic preference. International Journal of Corpus Linguistics, 9, 131-156. https://doi.org/10.1075/ijcl.9.1.07par

Phillip, G. (2009). "Why prosodies aren’t always there: insights into the idiom principle," at Corpus Linguistics Conference. Liverpool, Great Britain.

Sam, W. (2005). A critique of the concept of semantic prosody. International Journal of Corpus Linguistics 10(3), 283-305. https://doi.org/10.1075/ijcl.10.3.01whi

Shumin, K. (1997). Factors to Consider: Developing Adult EFL Students' Speaking Abilities. Forum, 35.

Sinclair, J. (1987). The nature of the evidence. In J. Sinclair (Ed.), Looking up (pp. 150-159). Glasgow: Collins.

Sinclair, J. (1991). Corpus, Concordance, Collocation. Oxford: Oxford University Press.

Sinclair, J. (1996). The search for units of meaning (pp. 75-106). Textus IX.

Sinclair, J. (2004a). The lexical item. In J. M. Sinclair (Ed.), Trust the Text. Language, Corpus and Discourse (pp. 131-148). London/NewYork: Routledge.

Sinclair, J. (2004b). The search for units of meaning. In J. M. Sinclair (Ed.), Trust the Text. Language, Corpus and Discourse (pp. 24-48). London/NewYork: Routledge.

Sorli, M. (2013). Forms of encoded pragmatic meaning: Semantic prosody - A lexicographic perspective. Lingue Linguaggi, 10, 95-111.

Stewart, D. (2010). Semantic Prosody: A Critical Evaluation. London/New York: Routledge. https://doi.org/10.4324/9780203870075

Stubbs, M. (1995). Collocations and semantic profiles: On the cause of trouble with quantitative studies. Functions of Language, 2(1), 23-55. https://doi.org/10.1075/fol.2.1.03stu

Stubbs, M. (2013). Sequence and order. The neo-Firthian tradition of corpus semantics. In H. Hasselgård, J. Ebeling, \& S. O. Ebeling (Eds.), Corpus Perspectives on Patterns of Lexis (pp. 13-34). Amsterdam/Philadelphia: John Benjamins. https://doi.org/10.1075/scl.57.04stu

Wang, H., \& Wang, T. (2005). A contrastive study on the semantic prosody of cause. Modern Foreign Language. 28(3), 297-307.

Wei, N. (2002). Research methods in the studies of semantic prosody. Foreign Language Teaching and Research, 34(4), 300-307.

Wei, N. (2006). A Corpus-based Contrastive Study of Semantic Prosodies in Learner English. Foreign Language Research, 132, 50-54.

Whitsitt, S. (2005). A critique of the concept of semantic prosody. International Journal of Corpus Linguistics, 10(3), 283-305. https://doi.org/10.1075/ijcl.10.3.01whi

Xiao, Z., \& McEnery, A. (2006). Collocation, Semantic Prosody, and Near Synonymy-A Cross-Linguistic Perspective. Applied Linguistics, 27(1), 103-129. https://doi.org/10.1093/applin/ami045

Zhang, C. (2010). An overview of corpus-based studies of semantic prosody. Asian Social Science, 6(6), 90-194. https://doi.org/10.5539/ass.v6n6p190

\section{Copyrights}

Copyright for this article is retained by the author, with first publication rights granted to the journal.

This is an open-access article distributed under the terms and conditions of the Creative Commons Attribution license (http://creativecommons.org/licenses/by/4.0/). 